\title{
Analysis of the 15 June 2013 Isolated Extreme Rainfall Event in Springfield, Missouri
}

\author{
W. SCOTT LINCOLN \\ National Weather Service Lower Mississippi River Forecast Center, Slidell, Louisiana
}

(Manuscript received 7 March 2014; review completed 22 May 2014)

\begin{abstract}
An isolated extreme rainfall event occurred across portions of the Springfield, Missouri, area on 15 June 2013, causing substantial flooding of several small headwater tributaries of the James River. Heavy, nearly stationary thunderstorm activity developed along an outflow boundary after 1500 UTC. This area of thunderstorms trained over southern Springfield before dissipating around 1845 UTC. Post-event analysis of rainfall amounts indicated both gauge observations and radar-derived estimates exceeding the 100-yr event (1\% annual chance equivalent). Local storm reports from the National Weather Service (NWS) forecast office in Springfield were supplemented with additional reports derived from news media and social media. Flash flood nowcasting techniques such as NWS gridded flash flood guidance (GFFG), rainfall average recurrence interval (ARI) estimates, the distributed hydrologic model-threshold frequency (DHM-TF), and the flooded locations and simulated hydrographs (FLASH) project were compared to local storm reports of flash flooding. A timeline of output from each of these techniques was compared to the time of reported flooding to evaluate the usefulness of each tool in the context of NWS operations. It was found that GFFG underestimated the scope of the flash flooding and would not have provided an estimate of flash flood severity. Rainfall ARI estimates, DHM-TF, and FLASH each suggested a significant flash flood event; however, DHM-TF output would have been available too late for forecasters and FLASH output would have provided several areas of false alarms. Rainfall ARI estimates provided the best balance of detecting areas of flash flooding, correctly estimating flash flood severity, and being available in a timely manner to NWS forecasters.
\end{abstract}

\section{Introduction}

An isolated extreme rainfall event occurred across portions of the Springfield, Missouri, area on 15 June 2013, causing substantial flooding of several small headwater tributaries of the James River. Isolated areas were analyzed to be at least a 100 -yr event $(1 \%$ annual chance equivalent) when looking at both 2-h and 3-h durations. There was very little lag time between the periods of heaviest rainfall and the worst impacts of flash flooding. Although flash flood warnings were issued by the National Weather Service (NWS) prior to reports of flooding, heightened wording (such as "flash flood emergency") was not used in a flood warning or statement until after the most severe flood impacts had begun. The ability to recognize extreme events as they unfold and provide severity-based product wording has been highlighted by several NWS service assessments (NWS 1999,
2010, 2011). Experimental techniques may provide a way to improve flash flood nowcasting and meet the goals of these assessments.

Discussing a flood in terms of a streamflow "return period" or "average recurrence interval" (ARI) has been used to describe the rareness of an event for many years. In recent years, the concept of describing rainfall in terms of an ARI also has been used to provide better context for extreme events. With the availability of improved updates to rainfall frequency analysis data across the contiguous United States, it has been proposed that rainfall ARIs can be estimated in real-time to better communicate flood severity as it unfolds, if not before it begins (Parzybok et al. 2011; Parzybok and Shaw 2012). Numerous experimental techniques utilizing both streamflow ARI and rainfall ARI are being tested with the goal of improving decision support services by NWS forecasters. 
This case study provides a brief meteorological overview of the 15 June 2013 event in the Springfield area and also discusses operational forecasting considerations. An emphasis is placed upon information that would have been available to warning forecasters prior to the onset of flooding. Section 2 provides a meteorological overview of the flash flood event; section 3 discusses various rainfall estimation methods; section 4 provides an overview of nowcasting methods compared to flooding reports; section 5 discusses strengths and weaknesses of each nowcasting method; and section 6 discusses conclusions that can be made from this case study.

\section{Meteorological aspects}

\section{a. Synoptic analysis}

The origins of the thunderstorm activity directly responsible for this event lie with a line of storms that formed in Nebraska and Iowa on 14 June. At 0300 UTC 15 June 2013, a surface low was analyzed near Omaha, Nebraska, with an associated weak warm front and stationary front extending southward toward the Gulf Coast (Fig. 1). The cluster of storms evolved into a squall line overnight, with the activity turning toward the south-southeast-almost parallel to the front. By 0900 UTC (Fig. 1), the line of thunderstorms was decaying as it moved into central Missouri, and an outflow boundary was analyzed along the leading edge of the activity. The low pressure area and associated stationary front had moved little over the 6-h period. By about 1200 UTC, most of thunderstorm activity had ceased along the outflow boundary, except for the western portion, which had slowed in its southward propagation. Over the 3 -h period from roughly 1200 to 1500 UTC, thunderstorm activity decreased in areal coverage, but increased in intensity just to the north of the Springfield area. The heaviest activity was sitting over the northeastern sections of Springfield by approximately 1400 UTC and was moving very slowly eastward, with storms continuing to build toward the southwest.

Surface winds were light through the event, generally $\leq 2.5 \mathrm{~m} \mathrm{~s}^{-1}$ (5 kt). The 1200 UTC sounding from NWS Weather Forecast Office (WFO) Springfield (located on the northwestern side of the city) indicated generally light winds up to about $400-\mathrm{mb}$, above which winds were $15-23 \mathrm{~m} \mathrm{~s}^{-1}$ (30-45 kt) from the west (Fig. 2). Although light, winds at $925-\mathrm{mb}$ were advecting somewhat warmer air from the southwest (Fig. 3a) and winds at $850 \mathrm{mb}$ were advecting slightly

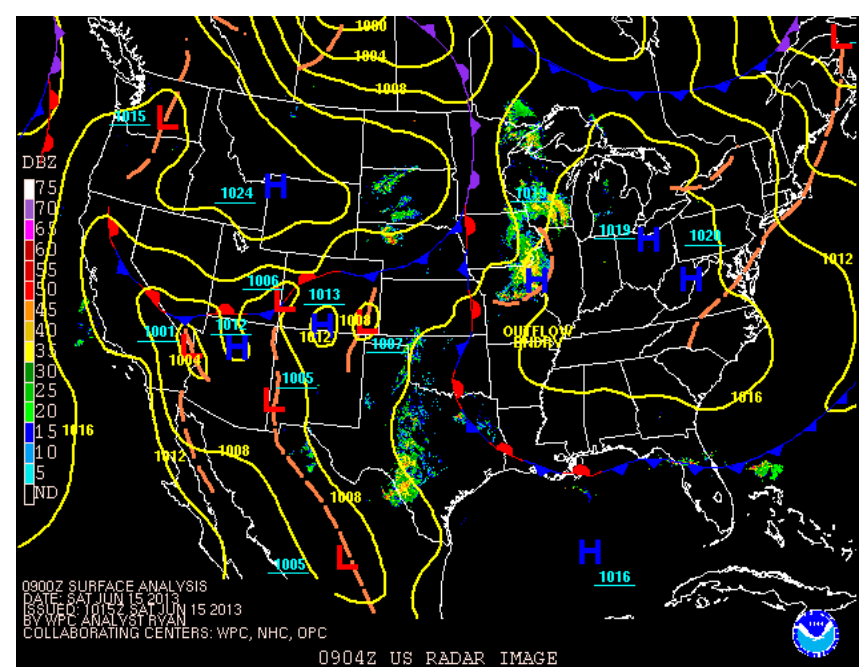

Figure 1. Hydrological Prediction Center surface analysis and radar composite for 0900 UTC 15 June 2013. Click image for an external animation valid from 0000 through 1800 UTC 15 June 2013.

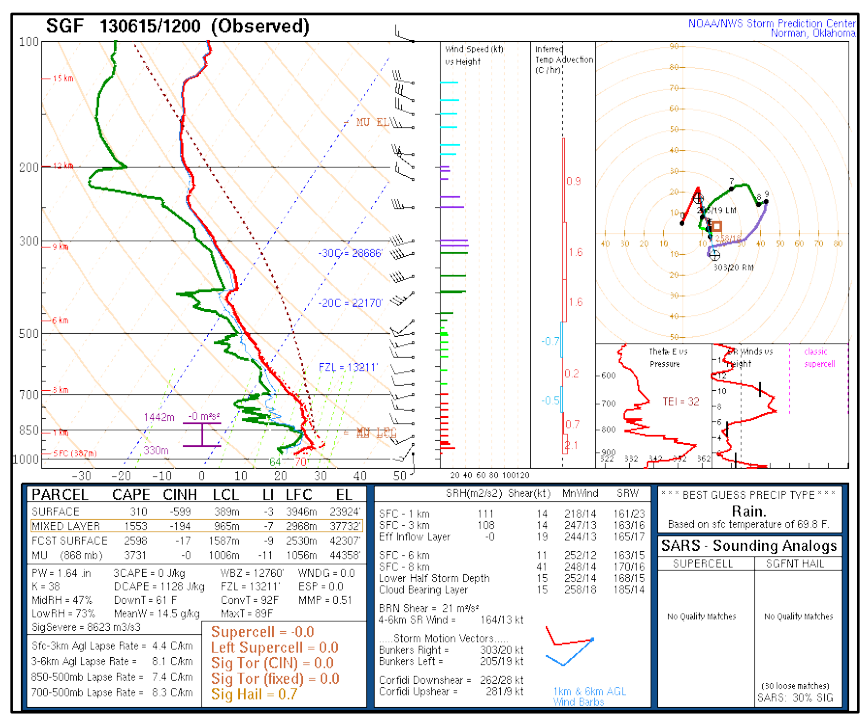

Figure 2. Sounding for the 1200 UTC 15 June 2013 launch from NWS WFO Springfield. Click image for an external version; this applies to all figures hereafter.

more moist air from the west (Fig. 3b). The $0^{\circ} \mathrm{C}$ and $-20^{\circ} \mathrm{C}$ levels were approximately $4025 \mathrm{~m}(13210 \mathrm{ft})$

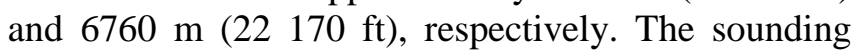
profile was rather moist, although the precipitable water $(4.17 \mathrm{~cm}$ or 1.64 in) was not particularly anomalous for June (80th percentile; Bunkers 2013). Southwestern Missouri was in an area of very light low-level (Figs. 3a and b) and midlevel winds just east of a 500-mb short-wave trough (Fig. 3c). Springfield was on the edge of a steep gradient toward higher precipitable water to the west (Fig. 3d). 


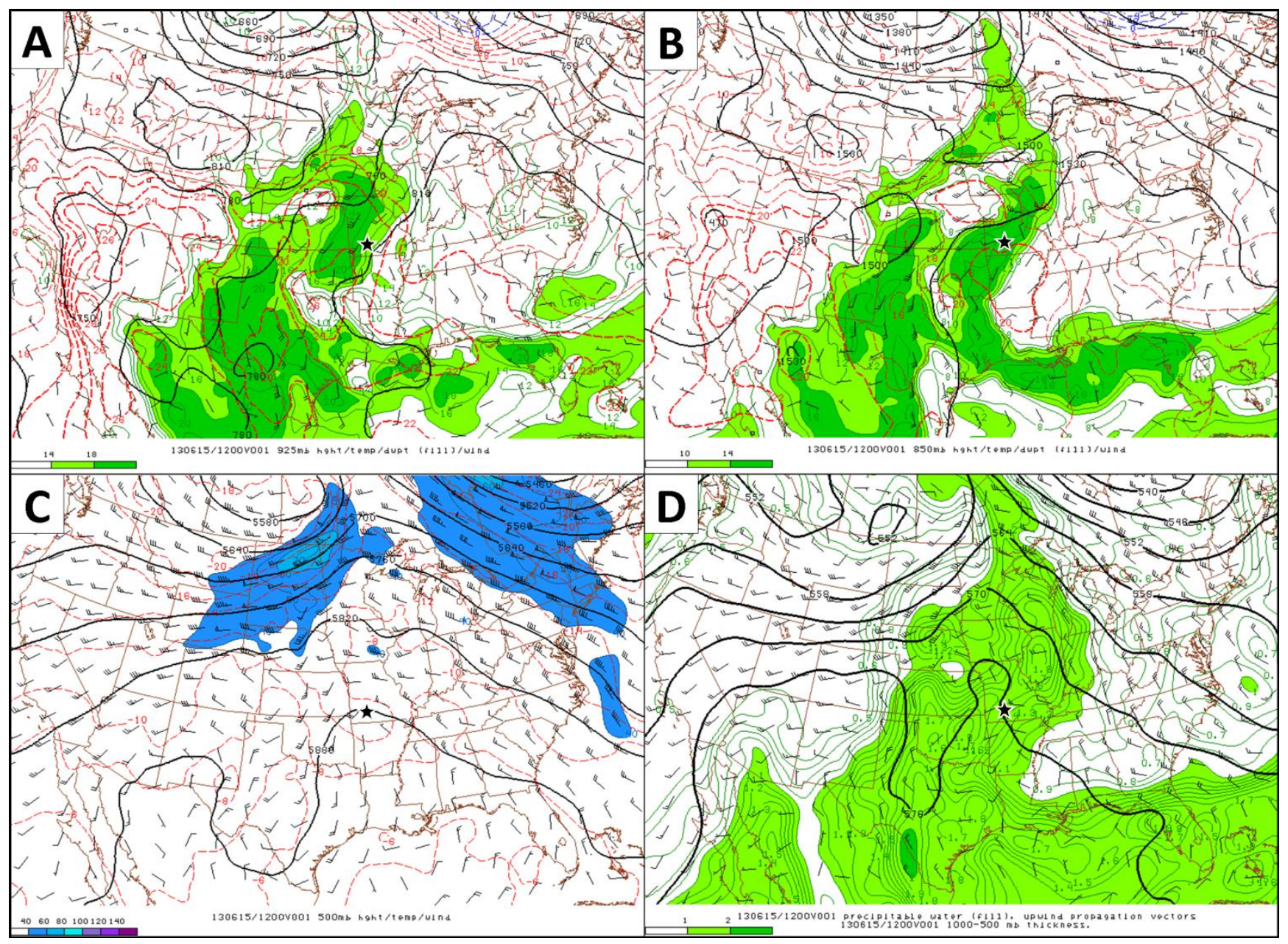

Figure 3. Storm Prediction Center mesoanalysis valid 1200 UTC 15 June 2013 for (a) 925 mb, (b) 850 mb, (c) 500-mb, and (d) the upwind propagation vectors combined with the precipitable water. A black star shows the location of Springfield. Displayed fields are wind (kt; multiply by 0.5144 for $\mathrm{m} \mathrm{s}^{-1}$ ), precipitable water (in; multiply by 2.54 for $\mathrm{cm}$ ), height (dam), and temperature and dewpoint $\left({ }^{\circ} \mathrm{C}\right.$ ).

\section{b. Radar analysis}

The thunderstorms directly responsible for producing the flash flood activity had formed by about 1500 UTC. One area of heavy rainfall was located just east of Springfield with another area forming on the southern side of the city as seen in the NWS WFO Springfield (KSGF) Next-Generation Radar (NEXRAD) (Fig. 4); these thunderstorms were nearly stationary. By 1600 UTC, the storm over southern Springfield became dominant and had stalled. Thunderstorm activity continued to develop over the same area of southern Springfield for nearly $3 \mathrm{~h}$ (1545-1845 UTC) until dissipating.

According to radar data from KSGF, the highest rainfall rates occurred over the far southern portions of Springfield near the Greene/Christian County line, just southwest of the James River Freeway (US 60) and Schoolcraft Freeway (US 65) interchange. The ex- treme nature of the event was due to nearly stationary thunderstorms training over the same location for a multiple-hour period.

\section{Rainfall estimation}

Rainfall data from numerous sources were obtained and analyzed for the period of heaviest rainfall on 15 June 2013. Rainfall data can be subdivided by its spatial coverage - meaning either point data such as from a rain gauge, or gridded data such as from remotely sensed estimates. Some of these data are available to forecasters in real-time and some data are only available after an event. This section elaborates on the different types of data used in this analysis. First is point rainfall data from official sources, then point rainfall data from partner agencies and the public, followed by gridded rainfall estimates. 


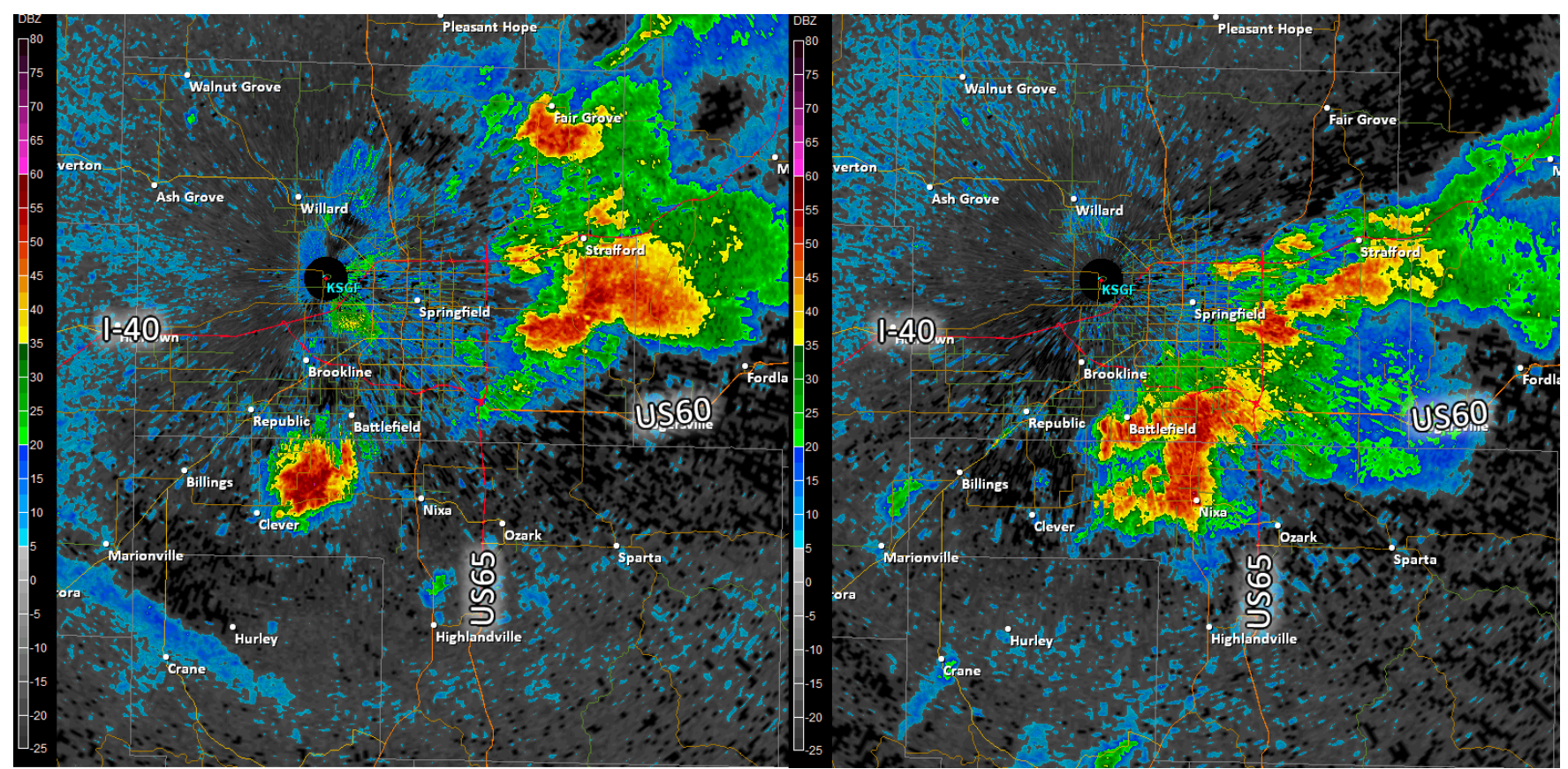

Figure 4. NEXRAD reflectivity (dBZ, scale at left of each image) from KSGF for the Springfield area at approximately 1500 UTC (left) and approximately 1600 UTC 15 June 2013 (right). Click image for an external animation valid from 1500 to 1845 UTC.

\section{a. Point rainfall data}

Point rainfall data were first obtained from official sites, which include the Automated Surface Observing System (ASOS; automated stations that typically are located at airports), United States Geological Survey (USGS; automated stations co-located with river observations), NWS Cooperative Observer Program (COOP; typically manual-reporting daily stations used for NWS climate records), and National Climatic Data Center (NCDC; long-term climate reporting stations). Of these, information from ASOS and USGS sites would typically be available in real-time to NWS forecasters. Next, point rainfall data were obtained from unofficial sites of partner agencies, which include the City of Springfield Public Works (automated gauges used for storm-water engineering) and the Community Collaborative Rain, Hail, and Snow Network (CoCoRaHS; typically manual-reporting daily stations monitored by a volunteer observer network). Of these, information from the Springfield rain gauge network typically would be available in realtime to NWS forecasters. Finally, point rainfall data were obtained from private sites, which include Weather Underground Personal Weather Station sites (WU PWS; automated stations of varying quality and reliability run by private persons or groups), local storm reports from trained spotters (LSR; rainfall measured, via unknown means, by NWS-trained per- sons, and called in to a local NWS office), and LSRs from the general public (rainfall measured, via unknown means, by persons of unknown training, and called in to a local NWS office). The locations of all rain gauge sites are shown in Fig. 5.

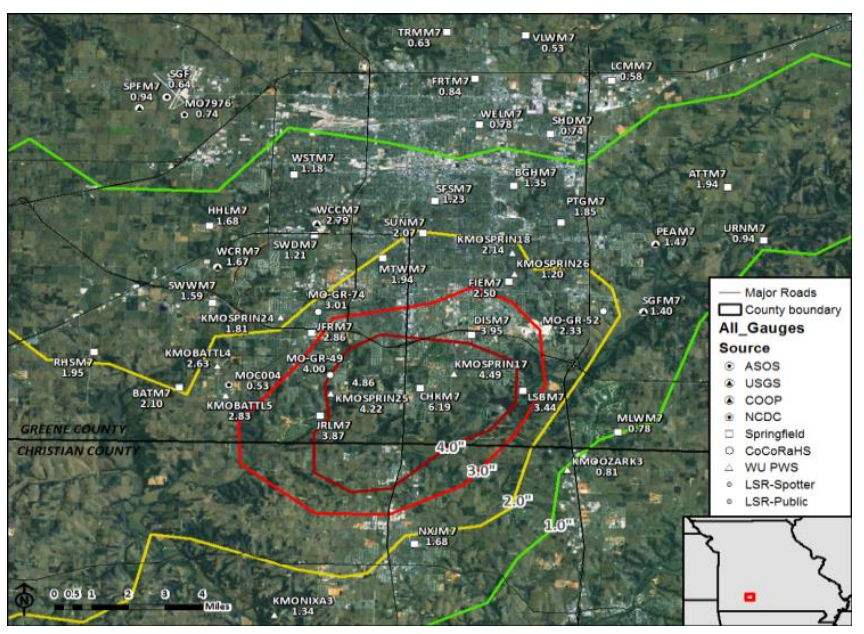

Figure 5. Locations of point rainfall data obtained for this analysis. Symbols represent the different sources of rainfall data. Subjective total rainfall contours (in; multiply by 2.54 for $\mathrm{cm}$ ) are provided for reference.

Rainfall data from ASOS, USGS, COOP, NCDC, and LSR sites were obtained from the Iowa Environmental Mesonet's archive (mesonet.agron.iastate.edu/ sites/locate.php). Data from CoCoRaHS sites were ob- 
tained from their data archive (www.cocorahs.org/ ViewData/) utilizing both single-day and multiple-day reports. Data from the City of Springfield rain gauge network were obtained from the project contractor's web portal (www.springfieldmo.gov/stormwater/ raingauge.html). Data from WU PWS sites were obtained from the Weather Underground archive (www.wunderground.com) after selecting relevant sites using the methods from Lincoln et al. (2013). Storm total rainfall from all gauge sites is shown in Fig. 5, with additional data for selected sites presented in Table 1. The rainfall reported at Cherokee Middle School $(15.7 \mathrm{~cm}$ or $6.19 \mathrm{in})$ is considered to be an isolated maximum. Two LSRs that were provided to NWS forecasters estimated rainfall totals of approximately $19.05 \mathrm{~cm}$ (7.5 in) and $22.86 \mathrm{~cm}$ (9.0 in), but their reported location put them very close to rainfall gauges that reported much lower totals $(9.83-12.34 \mathrm{~cm}$ or 3.87-4.86 in). Because their exact location could not be determined with high confidence, and because the reports were not consistent with other gauges in the area, they were not plotted.

\section{b. Gridded rainfall data}

Dual-polarization (dual-pol) NEXRAD data provide some of the quickest rainfall estimates available to NWS warning forecasters. The recently added dualpol capability has improved the ability of forecasters to discriminate between spherical rain drops, elongated rain drops, and rainfall mixed with hail-each of which has a different precipitation rate for a given reflectivity. The biggest strength of these estimates is that they are available for warning forecasters within minutes of the rainfall being detected by radar. Storm total rainfall from the dual-pol quantitative precipitation estimate (QPE) product is illustrated by Fig. 6.

Another radar-derived precipitation estimate available to forecasters in near real-time is Q2 (called Q3 since fall 2013), produced by the National Severe Storms Laboratory's (NSSL's) Multi-Radar MultiSensor System (MRMS; mrms.ou.edu/). Q2 differs from dual-pol radar estimates in that it is derived from multiple radars that have been seamlessly mosaicked. Short-term model data are compared with the character of radar reflectivity to determine the best radar-rainfall relationship. Storm total rainfall from the Q2 QPE product is illustrated by Fig. 7.

The official NWS QPE product (Fig. 8) created by the NWS River Forecast Centers (RFCs) is referred to as the multi-sensor best-estimate rainfall, and is cre-

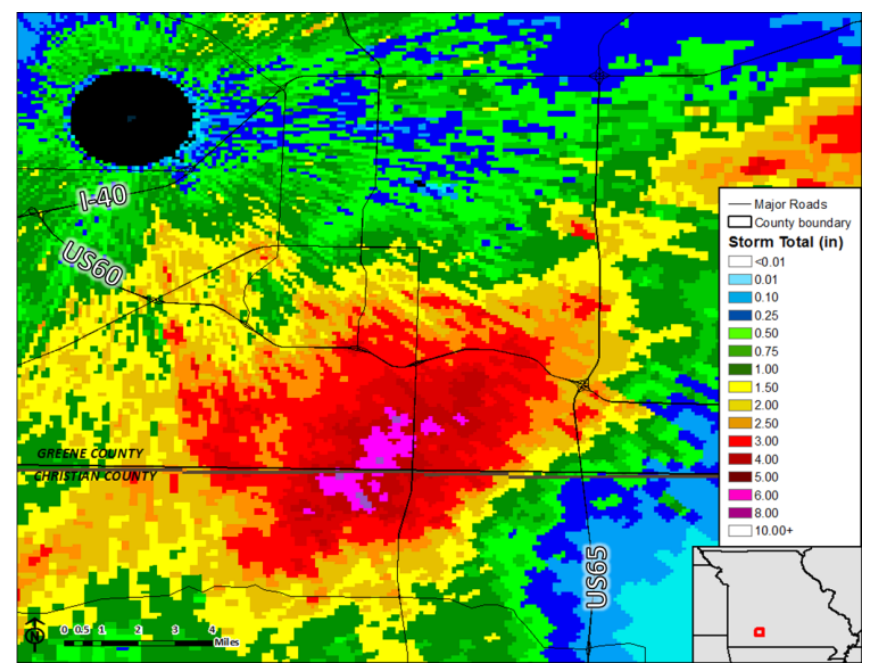

Figure 6. Storm total rainfall (in; multiply by 2.54 for $\mathrm{cm}$ ) for 15 June 2013 from the dual-pol QPE product.

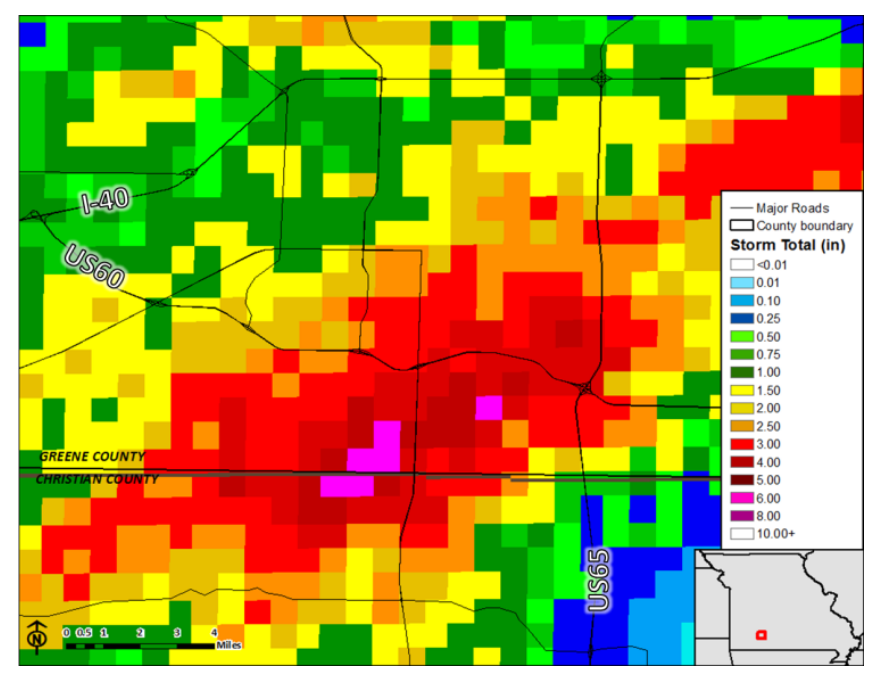

Figure 7. Same as Fig. 6 except for the MRMS Q2 product.

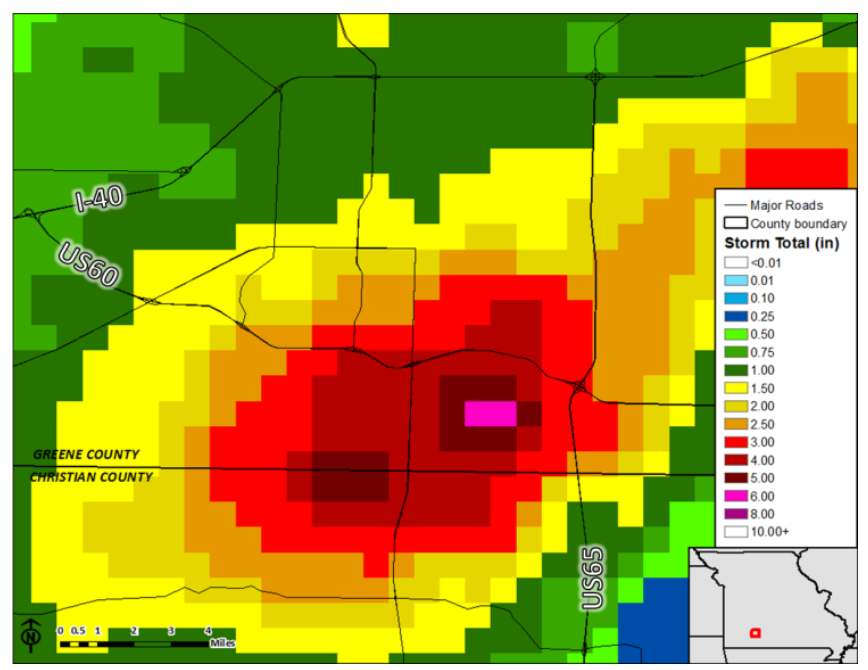

Figure 8. Same as Fig. 6 except for the NWS QPE product. 
Table 1. Selected rainfall amounts and ARIs for gauges in the Springfield area. Gauges that reported $<5.08 \mathrm{~cm}(2.0 \mathrm{in})$ of rainfall on 15 June 2013 are not included. The ARIs were estimated based upon data published in NOAA Atlas 14 (Perica et al. 2013) for the southern Springfield area $\left(37.1311^{\circ} \mathrm{N},-93.2767^{\circ} \mathrm{W}\right)$.

\begin{tabular}{|c|c|c|c|c|c|c|}
\hline Station & Data Source & $\begin{array}{c}\text { Storm Total Pcp } \\
\text { cm (in) }\end{array}$ & $\begin{array}{c}\text { Max 3-h Total Pcp } \\
\text { cm (in) }\end{array}$ & $\begin{array}{c}\text { Max 2-h Total Pcp } \\
\text { cm (in) }\end{array}$ & 3-h ARI (yr) & 2-h ARI (yr) \\
\hline \multirow[t]{2}{*}{ CHKM7 } & Springfield & $15.72(6.19)$ & $15.57(6.13)$ & $14.22(5.60)$ & 500 & 1000 \\
\hline & LSR-Public & $12.34(4.86)$ & & & & \\
\hline KMOSPRIN17 & WU PWS & $11.40(4.49)$ & $11.40(4.49)$ & $11.40(4.49)$ & 50 & 200 \\
\hline KMOSPRIN25 & WU PWS & $10.72(4.22)$ & $10.36(4.08)$ & $8.69(3.42)$ & 25 & 25 \\
\hline MO-GR-49 & CoCoRaHS & $10.16(4.00)$ & & & & \\
\hline DISM7 & Springfield & $10.03(3.95)$ & $9.86(3.88)$ & $8.61(3.39)$ & 25 & 25 \\
\hline JRLM7 & Springfield & $9.83(3.87)$ & $9.04(3.56)$ & $7.44(2.93)$ & 10 & 10 \\
\hline \multirow[t]{2}{*}{ LSBM7 } & Springfield & $8.74(3.44)$ & $8.38(3.30)$ & $7.75(3.05)$ & 10 & 10 \\
\hline & LSR-Spotter & $7.87(3.10)$ & & & & \\
\hline MO-GR-74 & CoCoRaHS & $7.65(3.01)$ & & & & \\
\hline JFRM7 & Springfield & $7.26(2.86)$ & $7.16(2.82)$ & $5.79(2.28)$ & 5 & 5 \\
\hline KMOBATTL5 & WU PWS & $7.19(2.83)$ & $6.58(2.59)$ & $5.82(2.29)$ & 5 & 5 \\
\hline WCCM7 & USGS & $7.09(2.79)$ & & $7.09(2.79)$ & & 10 \\
\hline KMOBATTL4 & WU PWS & $6.68(2.63)$ & $6.58(2.59)$ & $5.23(2.06)$ & 5 & 2 \\
\hline FIEM7 & Springfield & $6.35(2.50)$ & $6.10(2.40)$ & $5.41(2.13)$ & 2 & 2 \\
\hline MO-GR-52 & CoCoRaHS & $5.92(2.33)$ & & & & \\
\hline KMOSPRIN18 & WU PWS & $5.44(2.14)$ & $5.18(2.04)$ & $4.42(1.74)$ & 1 & 1 \\
\hline BATM7 & Springfield & $5.33(2.10)$ & $5.18(2.04)$ & 4.37 (1.72) & 1 & 1 \\
\hline
\end{tabular}

ated by mosaicking gridded radar estimates from individual radar sites, bias correcting the grids with automated rain gauges, then subsequently quality controlling the grids every hour. Hourly and daily data were obtained in geographical information system format from the NWS Advanced Hydrologic Prediction Service precipitation page (water.weather.gov/precip/).

The availability of rapidly updating, accurate precipitation estimates is vital to flash flood nowcasting. Estimates from dual-pol radar data and MRMS do update quickly, but substantial biases may exist owing to the use of remotely sensed data and imperfect algorithms. Rain gauges can help correct these biases, but typically do not update as quickly as the radar data. Estimates from the RFC-produced rainfall product generally are considered more accurate because of the inclusion of rain gauge bias correction; however, these estimates are only produced once per hour, and there is a 30-min delay before processing begins to allow rain gauge data to be transmitted into NWS systems. Thus, these official QPE estimates range from 0.5 to $1.5 \mathrm{~h}$ old by the time they are first available to warning forecasters for use in real-time operations. This dilemma causes all flash flood nowcasting techniques to either (1) use data with varying levels of uncertainty or (2) risk providing no lead time during a flash flood. Thus, it is important to understand which rainfall estimate is driving a particular flash flood nowcasting technique to better understand its limitations.

\section{c. Rainfall frequency analysis}

Gridded rainfall estimates can be compared to gridded rainfall frequency data to estimate the ARI of a storm like the Springfield event. The ARI is the average period of time between events of a given magnitude, when averaged over a very long period of time. The annual probability of a given event is equivalent to one divided by the ARI. A higher ARI, or lower annual percent chance, suggests a less frequent event; the frequency of an event has a rough association to event severity. ARI rainfall estimates are available from NOAA Atlas 14 (Perica et al. 2013), produced by the NWS Hydrologic Design Studies Center (HDSC). The HDSC computes ARI rainfall estimates for storms with durations ranging from $5 \mathrm{~min}$ to 60 days. Of these numerous storm durations, the 30-min, 1-h, 2-h, and 3-h durations are most relevant to this analysis.

The entire rainfall event lasted from 3 to $6 \mathrm{~h}$ across the Springfield area, with almost all rainfall occurring over a 3-h period and most rainfall occurring over a 2$\mathrm{h}$ period. The maximum 2- and 3-h rainfall accumulations were calculated for each rain gauge site when possible (the maximum 2- and 3-h accumulation periods were not necessarily the same for each gauge site). These values were then interpolated to a $0.01^{\circ} \times 0.01^{\circ}$ grid using the Kriging method and compared to the gridded ARI data from HDSC. The analyzed ARI for the 3-h duration is illustrated by Fig. 9. ARIs were 


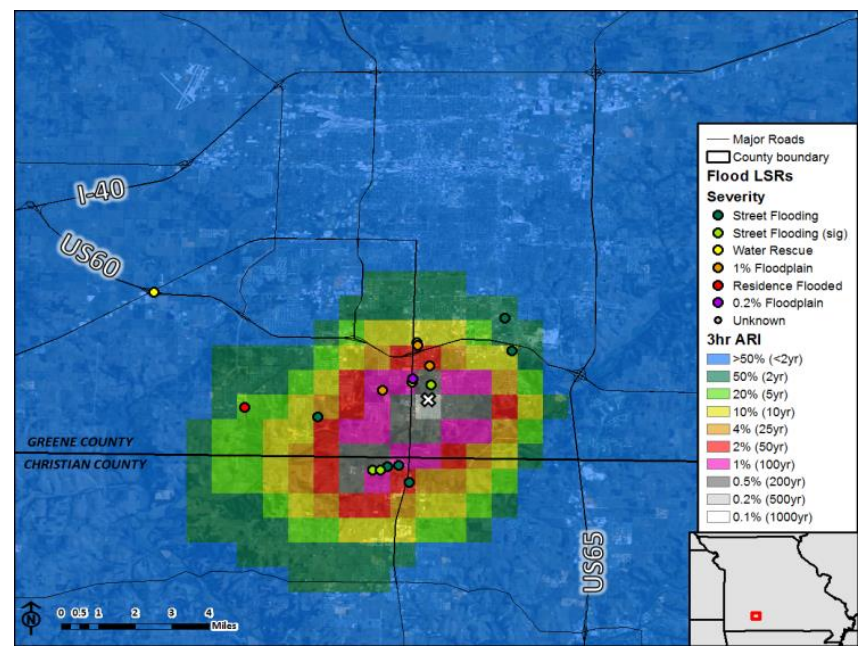

Figure 9. Estimated ARI for the highest 3-h rainfall during the 15 June 2013 event. The event could be classified as extreme (using $1 \%$ annual chance event threshold) for an area approximately 6.4 $\mathrm{km}(4 \mathrm{mi})$ east-west by $4.8 \mathrm{~km}(3 \mathrm{mi})$ north-south. The area surrounding Cherokee Middle School (marked with "X") was analyzed as a 500 -yr event ( $0.2 \%$ annual chance equivalent) using gridded rainfall estimates, although the site reported rainfall matching the 1000 -yr event $(0.1 \%)$ when looking at a 2-h duration. Flooding reports subjectively ranked by severity (see section $3 \mathrm{c}$ ) are added for reference.

very similar with both storm durations when viewed on a gridded basis. It also was noted that the ARI for Cherokee Middle School raw station observations was $1000 \mathrm{yr}(0.1 \%$ annual chance equivalent) for the heaviest 2-h rainfall, whereas it was only $500 \mathrm{yr}$ in the gridded analysis. Using either duration, the event could be classified as extreme (using 1\% annual chance event threshold) for an area approximately $6.4 \mathrm{~km}(4 \mathrm{mi})$ east-west by $4.8 \mathrm{~km}$ (3 mi) north-south.

Reports of flooding also can be compared to the rainfall frequency analysis to see how well the magnitude of the rainfall event compared to the magnitude of reported flooding. LSRs for the 15 June 2013 flash flood event were obtained from Iowa State University's Iowa Environmental Mesonet. Some manual quality control was required owing to (1) the coarse latitude and longitude resolution used by NWS records and (2) some obvious discrepancies between the described locations and their coordinates. When possible, the storm report remarks were used to move the flash flood reports to the correct location. Additional reports were added based upon photos from local media outlets such as the Facebook account of KOLR-TV and the Ozarks News-Leader newspaper, as well as videos posted by the public to YouTube. Flooding was subjectively categorized according to relative severity, ranging from least to most severe, as follows:
1) Minor nuisance flooding of roadways was classified as "Street Flooding."

2) Flooding of roadways deep enough to stall cars, or overtopping of bridges along major highways, was classified as "Significant Street Flooding."

3) Reports of persons needing to be rescued from residences or their vehicles were classified as "Water Rescue."

4) Evidence of water nearing or exceeding the Federal Emergency Management Agency (FEMA)designated 100-yr floodplain (1\% annual chance equivalent) was classified as " $1 \%$ Floodplain."

5) Reports of flooded residences were classified as "Residence Flooded."

6) Evidence of water nearing or exceeding the FEMA-designated 500-yr floodplain ( $0.2 \%$ annual chance equivalent) was classified as " $0.2 \%$ Floodplain."

7) Flooding reports with little additional information were classified as "Unknown."

Almost all reports of flooding matched closely to the area of 3-h rainfall ARIs exceeding a 2-yr event (50\% annual chance), with a general tendency for the most severe flooding reports to be toward the areas of more extreme rainfall (Fig. 9). The one exception to this would be the report of a water rescue near the James River Freeway (US 60) interchange with Sunshine Avenue. This water rescue appears to have occurred outside of the 2-yr event area. This section of the James River Freeway is relatively new and it seems unusual for a newly constructed arterial road to be overwhelmed by rainfall amounts that occur on a semi-frequent basis. It also should be noted that the James River runs right through the middle of the hardest hit area, limiting the flash flood reports in that area. After quality control of the LSR locations, it was found that the reports of flooding aligned closely with natural streams and drainages.

\section{Operational forecast considerations}

\section{a. Flash flood nowcasting techniques available to NWS warning forecasters}

Gathering all possible data for an analysis is certainly helpful in the context of accurate hindcasting; however, many data sources would not have been available just prior to the event when forecasters would need that information for a critical warning decision. To improve forecasting and nowcasting of extreme flood events, only the data that would have 
been available to a forecaster at the time of the forecast or nowcast were evaluated. In regards to the flash flood event in southern Springfield, some information was suggestive of not only flooding but uncommon flooding several minutes before reports were communicated to NWS offices. Other information available to forecasters before the event was less conclusive. Some tools available to NWS forecasters applicable to forecasting this type of flood event include real-time rainfall estimates from dual-pol NEXRAD data and NSSL's MRMS system, the gridded flash flood guidance (GFFG) produced by the NWS RFCs, the comparison of rainfall estimates to analyzed rainfall frequency data (section 3), and output from the experimental distributed hydrologic model-threshold frequency (DHM-TF) and experimental flooded locations and simulated hydrographs (FLASH) project. The various rainfall estimates were discussed in section 3. GFFG, DHM-TF, and FLASH are described in the following paragraphs.

GFFG is produced four times daily $(0000,0600$, 1200, and 1800 UTC) by NWS RFCs and provides a rainfall threshold (for 1-, 3-, and 6-h storm durations) which, when exceeded, is expected to cause flash flooding. GFFG is derived from gridded land-use and soil data, and varies based upon changes in modeled soil moisture. GFFG is ingested into the Flash Flood Monitoring and Prediction software at NWS WFOs, where it is averaged over small stream basins and compared to WFO-defined rainfall estimates in realtime.

The DHM-TF is an experimental flash flood nowcasting technique developed at the NWS's Office of Hydrologic Development (Reed et al. 2007; Cosgrove et al. 2012), which models surface water runoff from RFC rainfall estimates. The model was designed to have the exact same grid spacing as the RFC multisensor rainfall product (approximately $4 \mathrm{~km} \times 4 \mathrm{~km}$ ). The DHM-TF compares modeled surface water flow in real-time to modeled surface water flow over the period of record (the length of available rainfall data) to estimate an ARI at each grid cell. Thus, this technique is in contrast to rainfall ARIs in that it indicates where runoff is accumulating rather than where it is generated; because of this, the DHM-TF should be more directly comparable to the severity of flooding than rainfall ARIs. This methodology also reduces uncertainty from lack of calibration by comparing real-time biased output to historical biased output. Unfortunately, the DHM-TF is driven by the RFC rainfall estimates, which can introduce a lag time of up to $1.5 \mathrm{~h}$ between rain hitting the ground and model output becoming available. The maximum streamflow ARIs from the DHM-TF compared to the flooding LSRs are illustrated by Fig. 10. Streamflow in the pixels representing Ward Creek reached ARIs up to 27 yr (4\% annual chance equivalent). A 20 -yr event (5\%) is considered very significant for this technique because the baseline period of record is about $10 \mathrm{yr}$, and ARIs of roughly twice the period of record length are widely considered the limit of reasonable extrapolation (Swain et al. 2004; Raiford et al. 2007; UCAR 2014). Also of note is the cluster of flood reports south of Ward Creek that are in an area of $\leq 2 \mathrm{yr}(\leq 50 \%$ annual chance equivalent). This grid cell represents the James River, which has a much larger contributing area than Ward Creek, and most of which received only light rainfall.

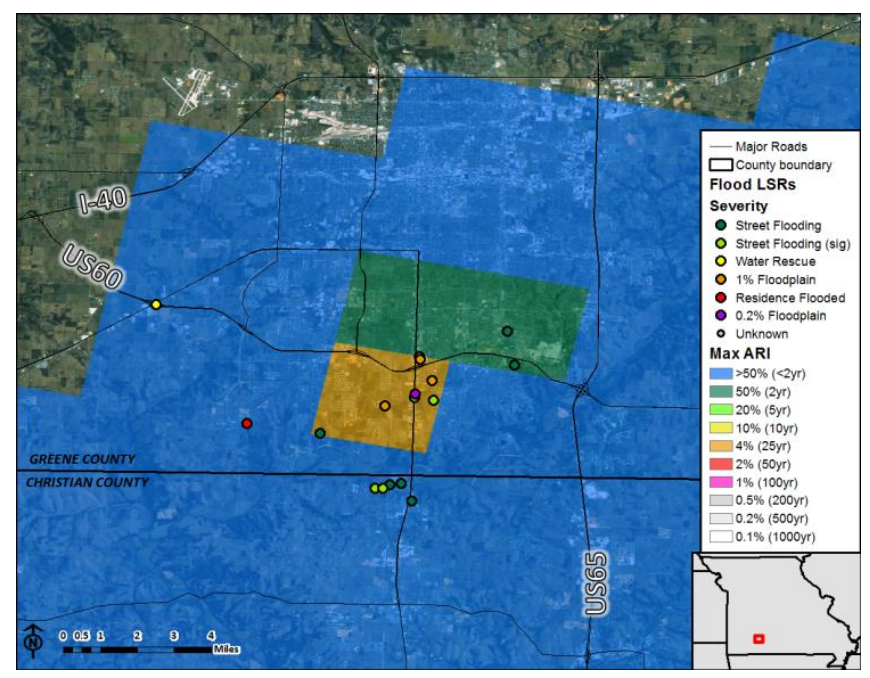

Figure 10. Maximum streamflow ARIs from DHM-TF compared to reports of flooding. Flooding reports are subjectively ranked by severity (see discussion in section $3 \mathrm{c}$ ).

The FLASH project is an experimental flash flood nowcasting technique similar to the DHM-TF in that it attempts to model where runoff accumulates and compares surface water flow to historical conditions (blog.nssl.noaa.gov/flash/). FLASH differs in rainfall forcing; it is driven by estimates from the Q2 rainfall product instead of the RFC QPE rainfall product used by DHM-TF. FLASH updates more quickly but may be susceptible to higher uncertainty owing to the higher uncertainty in the rainfall data. The maximum streamflow ARIs from the FLASH project compared to the flooding LSRs are illustrated by Fig. 11. Output from FLASH suggested that many portions of Springfield would experience flooding, exceeding $200 \mathrm{yr}$ 


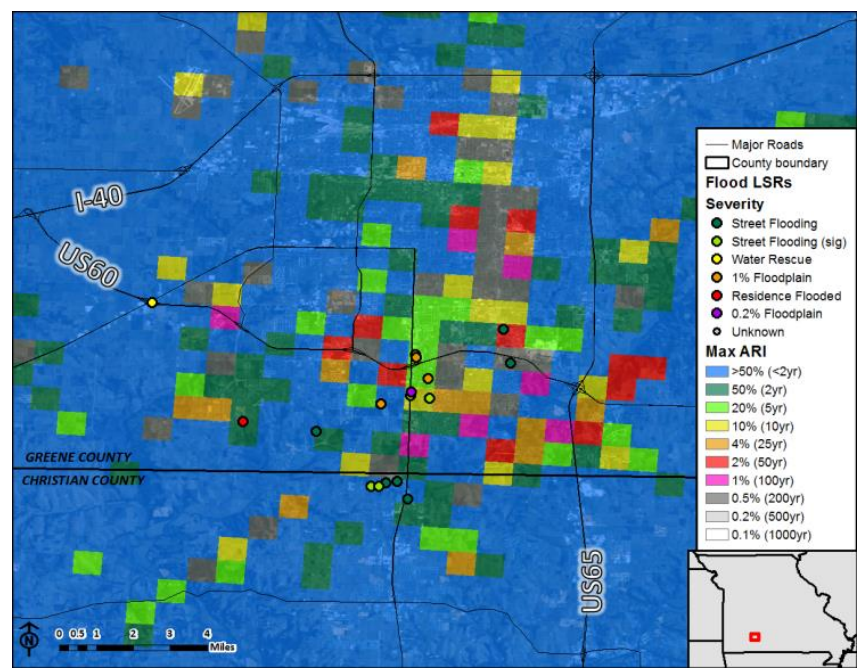

Figure 11. Same as Fig. 10 except for FLASH.

( $0.5 \%$ annual chance equivalent) in some areas. ARIs of this magnitude are far beyond values considered very significant for this technique because the baseline period of record is only about $10 \mathrm{yr}$ (see DHM-TF discussion above). In many cases, the modeled areas of worst flooding did not line up with the storm reports of flooding.

\section{b. 15 June flash flood timeline}

The first local storm reports came in to the NWS WFO Springfield office around 1717 UTC 15 June and these reports continued to come in through about 1900 UTC. For the purposes of this analysis, 1715 UTC is considered to be the onset of flash flooding of high enough severity to warrant a report to the NWS. The following sections analyze what information would have been available to NWS forecasters with varying degrees of lead time. NWS warning statements are compared to running accumulations of rainfall in Fig. 12.

\section{1) 30 MIN OF LEAD TIME (1645 UTC)}

At 1645 UTC, NWS forecasters would have had an estimated $30 \mathrm{~min}$ of lead time for the event. Heavy rainfall had been occurring near the Cherokee Middle School area for about an hour and was nearing an accumulation of almost $8.89 \mathrm{~cm}$ (3.5 in). A nearly stalled thunderstorm continued to reform over the same areas of southern Springfield. The 1-h rainfall barely exceeded GFFG values, but was already higher than the 50 -yr event ( $2 \%$ annual chance equivalent) based upon historical rainfall frequency data (Fig. 13a).

\section{2) 25 MIN OF LEAD TIME (1650 UTC)}

Output from the DHM-TF utilizing RFC rainfall estimates ending at 1600 UTC finished processing at approximately 1650 UTC. No areas of significant streamflow were indicated by output from the DHMTF (Fig. 14a).

\section{3) 15 MIN OF LEAD TIME (1700 UTC)}

At 1700 UTC, NWS forecasters had an estimated $15 \mathrm{~min}$ of lead time for the event. Heavy rainfall had been occurring near the Cherokee Middle School area for almost $1.5 \mathrm{~h}$ and was nearing an accumulation of almost $11.43 \mathrm{~cm}$ (4.5 in). The nearly stationary thunderstorm remained over portions of southern Springfield. The 1-h rainfall was still barely exceeding GFFG values but continued to exceed the $50-\mathrm{yr}$ event (2\% annual chance equivalent) based upon historical rainfall frequency data (Fig. 13b).

\section{4) -35 MIN OF LEAD TIME (1750 UTC)}

Output from the DHM-TF utilizing RFC rainfall estimates ending at 1700 UTC finished processing at approximately 1750 UTC. This was the first hourly update of the DHM-TF that indicated areas of significant streamflow (2-yr event or greater) in the Springfield area (Fig. 14b). The grid cell that covers the area of most severe flooding (Ward Branch) yielded a streamflow ARI of $9 \mathrm{yr}$ (11.1\% annual chance equivalent).

\section{5) -95 MIN OF LEAD TIME (1850 UTC)}

Output from the DHM-TF utilizing RFC rainfall estimates ending at 1800 UTC finished processing at approximately 1850 UTC. The grid cell covering Ward Branch now yielded a streamflow ARI of $27 \mathrm{yr}$ (3.7\% annual chance equivalent; Fig. 14c), which is near the maximum reasonable extrapolation for a technique with this period of record. This hourly update of the DHM-TF suggested the highest streamflow ARIs; after this point, streamflow ARIs for Ward Branch began to decrease.

\section{6) -155 MIN OF LEAD TIME (1950 UTC)}

Output from the DHM-TF utilizing RFC rainfall estimates ending at 1900 UTC finished processing at approximately 1950 UTC. The grid cell covering Ward Branch yielded a streamflow ARI of $15.5 \mathrm{yr}$ 


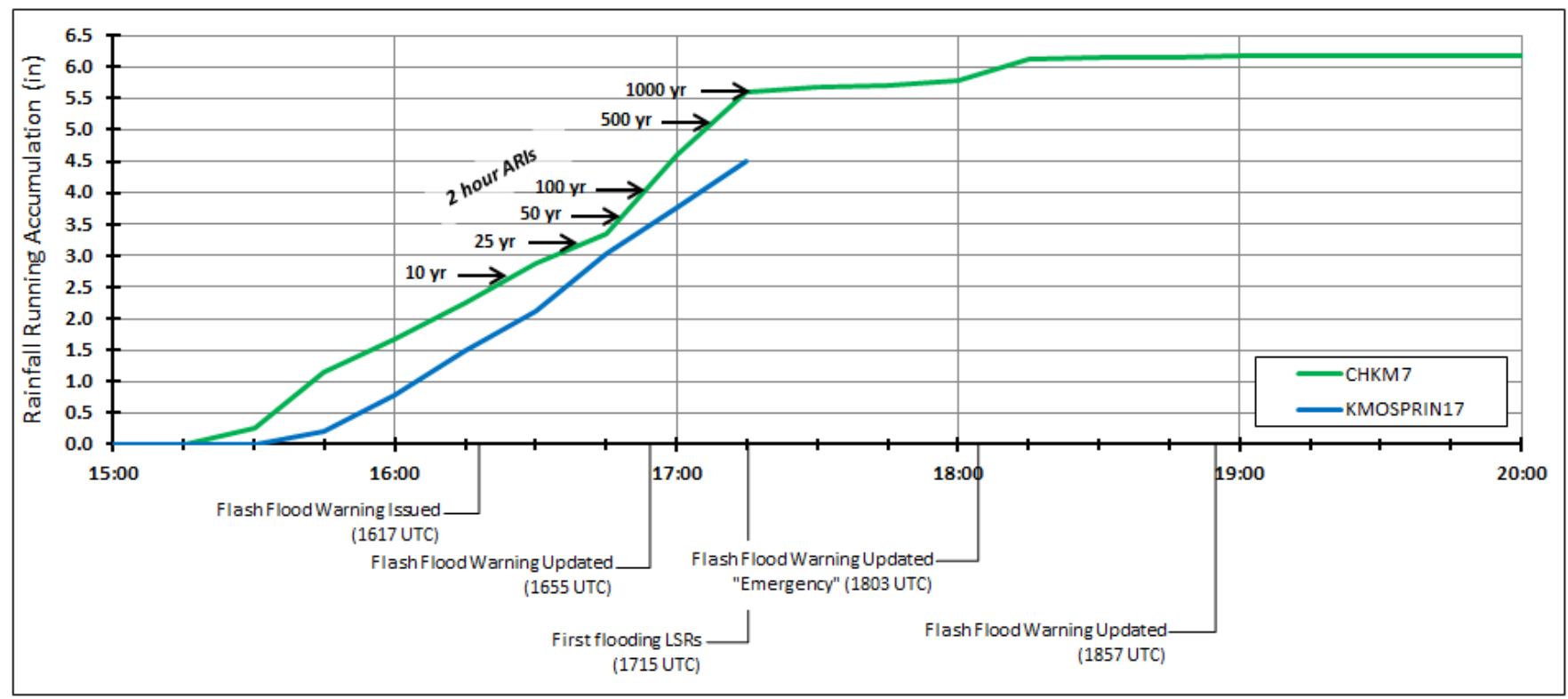

Figure 12. Running rainfall accumulation (in; multiply by 2.54 for $\mathrm{cm}$ ) for two rain gauge sites in the area of heaviest rainfall compared to a timeline of flash flood statements. Site CHKM7 is the Cherokee Middle School location operated by the City of Springfield, and site KMOSPRIN17 is a nearby private gauge that transmits to Weather Underground. Data were lost for site KMOSPRIN17 around the time flash flood reports arrived at NWS Springfield, likely due to a power or internet failure. The 2-h rainfall ARI for site CHKM7 is added to the running accumulation for reference.
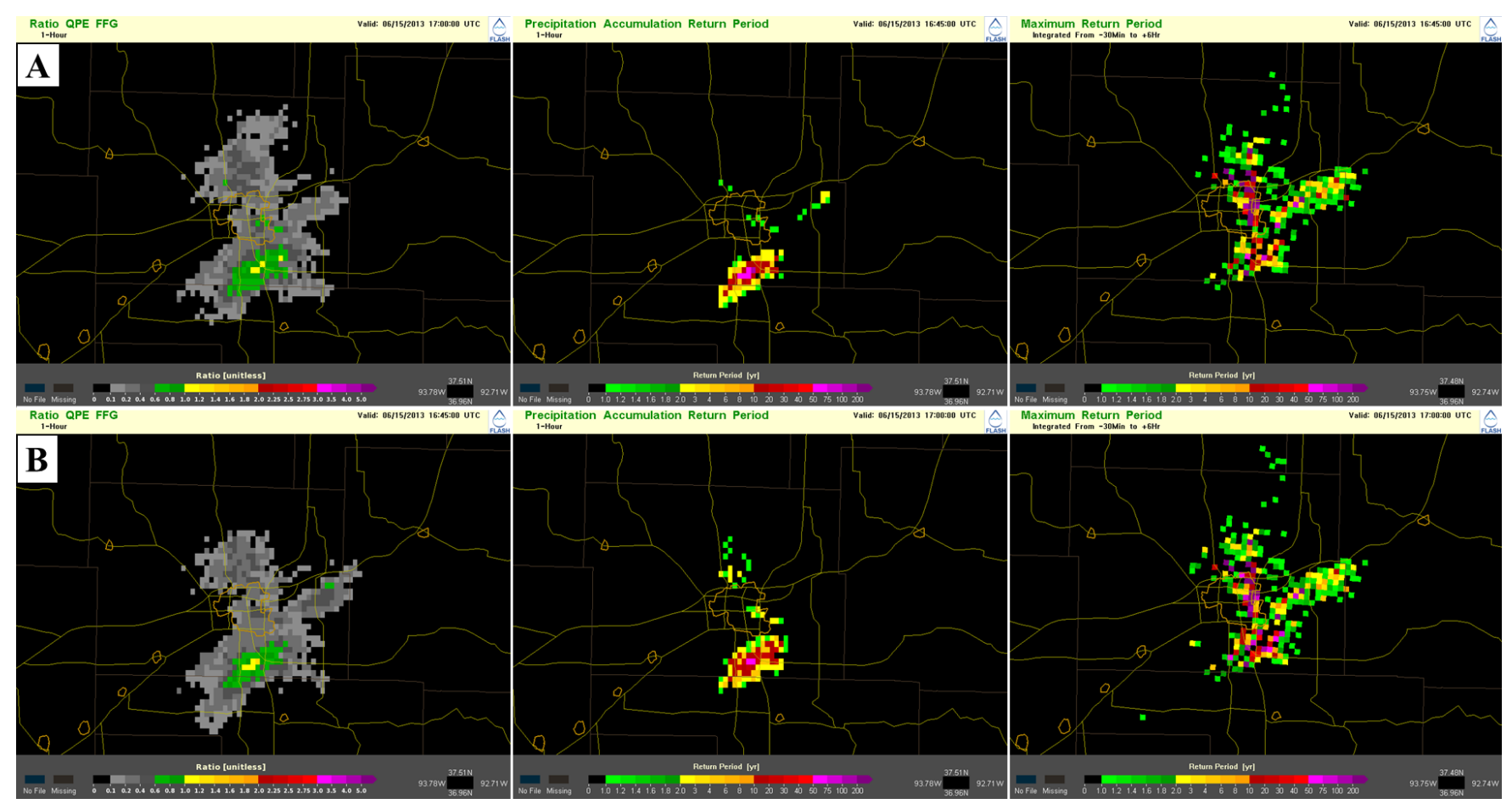

Figure 13. The 1-h GFFG ratio (left column), 1-h rainfall ARI (middle column), and FLASH streamflow ARI (right column) for 1645 UTC (top row) and 1700 UTC (bottom row) obtained from NSSL's FLASH system. 1645 UTC and 1700 UTC correspond to approximately $30 \mathrm{~min}$ and $15 \mathrm{~min}$ of lead time, respectively. The area of heaviest rainfall (between Springfield and the Greene/Christian County line) is depicted as barely exceeding GFFG, but is shown to be at least a 50 -yr event ( $2 \%$ annual chance equivalent) when compared to historical rainfall frequency data. Streamflow ARIs across many portions of Springfield exceeded the 50 -yr event (2\% annual chance equivalent). 


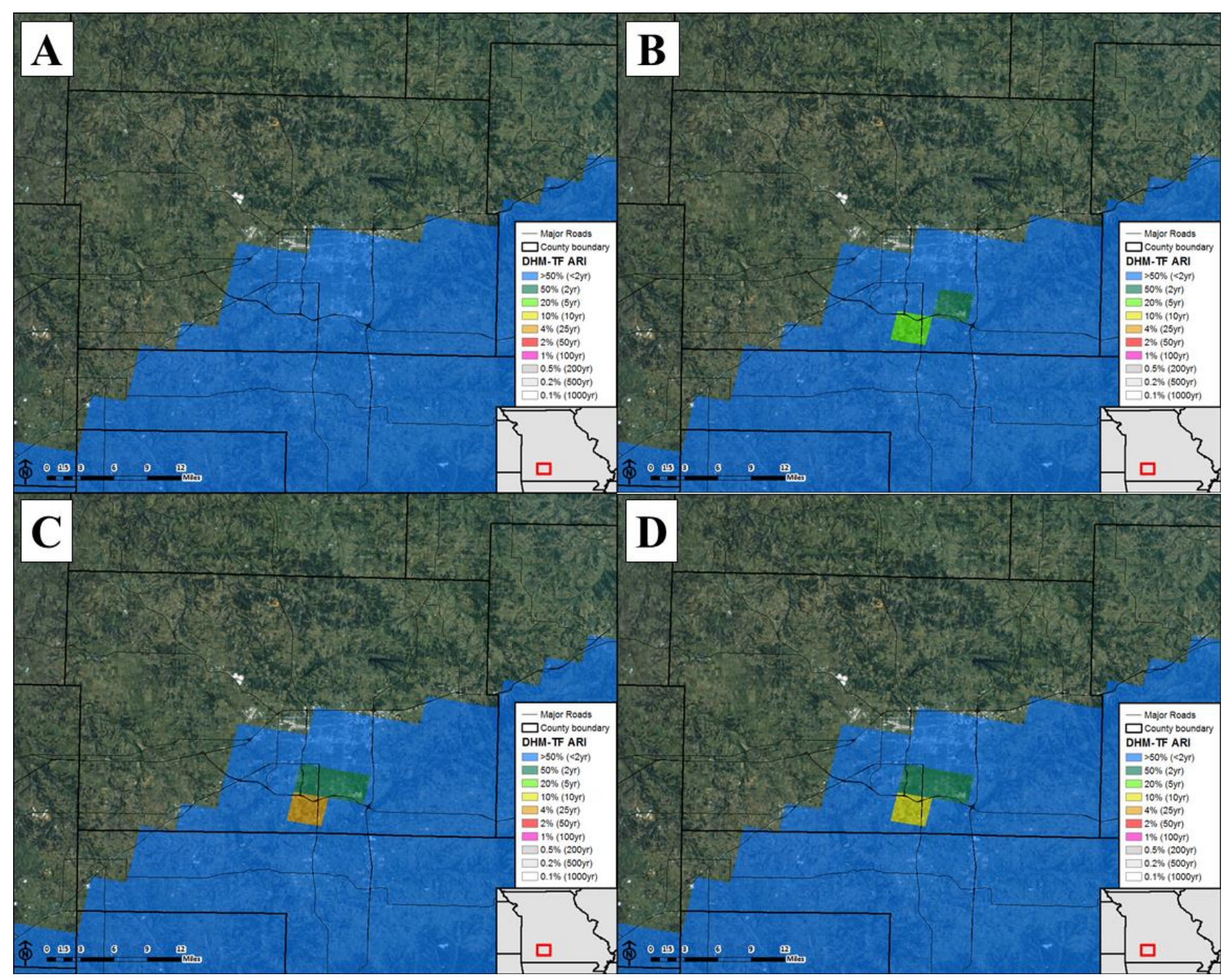

Figure 14. Output from the DHM-TF modeling experiment based upon RFC rainfall estimates up through (a) 1600 UTC, (b) 1700 UTC, (c) 1800 UTC, and (d) 1900 UTC. Results were available to NWS forecasters at 50 min past the hour.

(6.5\% annual chance equivalent; Fig. $14 \mathrm{~d})-\mathrm{a}$ decrease in severity since the previous hour.

\section{Discussion}

The 15 June 2013 event was not one that forecasters would typically view as favorable for flash flooding. Precipitable water was above average, but not particularly anomalous, based upon nearby sounding data. An outflow boundary from a line of decaying thunderstorms was the focus for nearly stationary, heavy thunderstorms to form over portions of Springfield. Data suggest that these storms were not dominated by warm rain processes as is seen in many missed flash flood events. The slow movement of the storms was the main factor in the extreme rainfall.
Although the atmospheric conditions did not provide substantial alarm for the potential of flash flooding, the event (including its uncommon magnitude) was somewhat predictable prior to the onset of flooding. The main tool used by local NWS offices to determine if flash flood warnings are necessary is the GFFG product produced by the NWS RFCs. For this event, the operational GFFG product was not particularly useful. Although rainfall did exceed GFFG values suggesting that flooding was possible, the rainfall barely exceeded the flooding threshold suggesting a marginal event. When looking at experimental rainfall comparisons to historical rainfall frequency data, the magnitude of the event was much more apparent. Even 30 min prior to the first report of flooding in the area, 
the 1-h ARI indicated rainfall exceeding the 50-yr event (2\% annual chance equivalent), suggesting flooding of an uncommon, near-extreme magnitude.

An analysis of rainfall events in the context of historical rainfall frequency is not a new concept, although this is typically done after an event. During the summer of 2013, NSSL added estimates of 1- and 2-h rainfall ARIs to their experimental FLASH site. The rainfall that drives the estimates is the radar-only Q2 product (called Q3 since summer 2013) derived from the MRMS national three-dimensional mosaic of radar data from across the contiguous United States. Although no bias correction is applied, rainfall data from Q2 have much more frequent updates than rainfall data from NWS RFCs and are available much more quickly. Rainfall data from NWS RFCs can be up to $1.5 \mathrm{~h}$ old after bias correction and human quality control. In contrast, Q2 data and their derivatives are typically available within $15 \mathrm{~min}$. Another benefit to using real-time rainfall ARI estimates is that it can dramatically reduce the area indicated as likely to experience flooding. For the 15 June case, every report of flooding except for one was located within the area of at least 2-yr ARI (50\% annual chance equivalent), and most of the more severe flooding impacts were in the higher magnitude rainfall ARIs. Note that rainfall severity may not relate directly to flooding severityespecially on larger scales-owing to many factors, including seasonal vegetation differences, soil moisture variability, differences in terrain, and human interaction with natural terrain. Because of this, caution should be used when applying rainfall severity as a proxy for flash flood severity. Usage of radar-only rainfall estimates from Q2 also requires forecaster awareness of potential rainfall biases that could cause an underestimate or overestimate in the ARI products.

Another caveat to using rainfall ARI (as well as GFFG) as a flash flood nowcasting technique is that it does not contain any routing of runoff to downstream locations. Some flash flood impacts are noted downstream of where the runoff is generated, in some cases being outside of the area of rainfall. Experimental tools such as the DHM-TF and FLASH are being developed to address this issue. Both techniques provide an estimate of streamflow ARI rather than rainfall ARI. Theoretically, output from these models should match most closely to actual reports of flash flooding. For the 15 June case, both the DHM-TF and FLASH outputs were less helpful than the rainfall ARIs. DHM-TF did eventually indicate significant ARIs, but unfortunately the output would not have been available to NWS forecasters until approximately 1800 UTC - about an hour later than the first flooding reports. Output from FLASH was available at much more frequent intervals with a much shorter delay, but it indicated many areas of Springfield would experience extreme flooding, which did not relate to a single report. The approximate centroid of the highest ARIs from FLASH also did not match up with the flood reports.

\section{Conclusions and future work}

The 15 June 2013 flash flood of southern Springfield, Missouri, was caused by an isolated area of very slow-moving thunderstorms that produced very heavy rainfall over a 3 -h period. Best estimates of storm total rainfall from a combination of radar data and numerous rain gauge sites operated by various entities suggest an event with $<1 \%$ chance of occurring in a given year, also referred to as a $100-y r$ event. Isolated locations may have experienced rainfall within a 2-h period of the event that matched rainfall with only a $0.1 \%$ chance of occurrence in a given year (1000-yr event). This rainfall caused the flooding of several creeks in the area that impacted multiple major arterial roadways and at least one residence.

This flood event is yet another case that demonstrates the need for multiple flood forecasting tools and techniques. For this event, almost all techniques, both traditional and experimental, had limitations. Some techniques provided a reasonable estimate of flood severity, but data would not have been available to forecasters before the onset of flooding. Other techniques indicated flooding, but yielded many areas of false alarms. For this event, the technique that appeared to best match both the location and severity of flooding was the rainfall ARI product, although it should be expected that the best-performing technique will vary by event.

As with meteorological forecasting in the NWS, real-time nowcasting of high-impact hydrologic events will be greatly improved with the availability of multiple tools and techniques used by a trained, critically thinking forecasting staff in real-time. Useful warnings require not only a statement on the possibility of an event, but a reasonable estimate of the event magnitude. Flash flooding continues to be one of the biggest threats to lives and property in the United States. The NWS should continue to support new tools and techniques to address the threat. 
Acknowledgments. The author acknowledges Weather Underground as the source for private weather station data. Daryl Herzmann and the Iowa Environmental Mesonet from Iowa State University are acknowledged as the source for processed NMQ/Q2 radar precipitation data. Volunteer observers for the CoCoRaHS program in the Springfield area are acknowledged for their valuable information that can be used to corroborate estimates from other gauge networks. The author also acknowledges the City of Springfield for the dense rain gauge network that provided invaluable data to this analysis, including the rainfall maximum. The author also thanks David Schlotzhauer and Jeff Zogg for their helpful comments, as well as the two reviewers who provided valuable feedback.

\section{REFERENCES}

Bunkers, M. J., cited 2013: Upper-air climatology plots. [Available online at www.crh.noaa.gov/unr/?n=pw.]

Cosgrove, B. A., E. Clark, S. Reed, V. Koren, Z. Zhang, Z. Cui, and M. Smith, 2012: Overview and initial evaluation of the distributed hydrologic model threshold frequency (DHM-TF) flash flood forecasting system. NOAA Tech. Rep. NWS 54, 60 pp. [Available online at docs.lib.noaa.gov/noaa documents/NWS/ TR_NWS/TR NWS 54.pdf.]

Lincoln W. S., J. Brazzel, M. Pope, R. McNeil, D. Schlotzhauer, K. Costanza, J. Graschel, and S. Van Cooten, 2013: 2012 southeast Louisiana and southern Mississippi flooding due to Hurricane Isaac. NWS River Forecast Center Tech. Paper, 96 pp. [Available online at www.srh.noaa.gov/images/lmrfc/tech/ 2012_Hurricane_Isaac_Flooding_techmemo_manuscrip t_2013_11_15.pdf.]

NWS, 1999: South Texas floods October 17-22, 1998. NWS Service Assessment, 34 pp. [Available online at www.nws.noaa.gov/om/assessments/pdfs/txflood.pdf.] , 2010: Southeast United States floods, September 1823, 2009. NWS Service Assessment, 71 pp. [Available online at www.nws.noaa.gov/om/assessments/pdfs/ se floods10.pdf.]
,2011: Record floods of greater Nashville: Including flooding in middle Tennessee and western Kentucky, May 1-4, 2010. NWS Service Assessment, 93 pp. [Available online at www.nws.noaa.gov/om/ assessments/pdfs/Tenn_Flooding.pdf.]

Perica, S., and Coauthors, 2013: NOAA Atlas 14 Precipitation-Frequency Atlas of the United States. NWS HDSC, Volume 8, Version 2, 297 pp. [Available online at www.nws.noaa.gov/oh/hdsc/PF_documents/ Atlas14_Volume8.pdf .]

Parzybok, T. W., and B. L. Shaw, 2012: Forecast average recurrence interval precipitation maps for the United States: A new way of communicating the location and magnitude of high impact precipitation events. Preprints, 26th Conf. on Hydrometeorology, New Orleans, LA, Amer. Meteor. Soc., 5.1. [Available online at ams.confex.com/ams/92Annual/webprogram/ Paper196778.html.]

, B. Clarke, and D. M. Hultstrand, 2011: Real-time average recurrence interval rainfall maps for the U.S. Preprints, 39th Conf. on Broadcast Meteorology, Oklahoma City, OK, Amer. Meteor. Soc., 6.1. [Available online at ams.confex.com/ams/ 39BROADCAST/webprogram/Paper189032.html.]

Raiford, J. P., N. M. Aziz, A. A. Khan, and D. N. Powell, 2007: Rainfall depth-duration-frequency relationships for South Carolina, North Carolina, and Georgia. Am. J. Environ. Sci., 3, 78-84, CrossRef.

Reed, S., J. Schaake, and Z. Zhang, 2007: A distributed hydrologic model and threshold frequency-based method for flash flood forecasting at ungauged locations. J. Hydrol., 337, 402-420, CrossRef.

Swain, R. E., J. F. England Jr., K. L. Bullard, and D. A. Raff, 2004: Hydrologic hazard curve estimating procedures. Bureau of Reclamation Research Report DSO-04-08, 85 pp. [Available online at www.nwdwc.usace.army.mil/PB/HHCOP/DSO-04-08.pdf.]

UCAR, cited 2014: Flood frequency analysis. University Corporation for Atmospheric Research, Cooperative Program for Operational Meteorology, Education, and Training (COMET), Boulder, CO. [Available online at www.meted.ucar.edu/hydro/basic/FloodFrequency/.] 